\title{
The causes of developmental deformity and their implication for seating
}

\author{
D. SCRUTTON \\ Newcomen Centre, Guy's Hospital, London, UK
}

\begin{abstract}
This article attempts to touch upon several different aspects of developmental deformity. It is intended to show that the position in which children are placed and the time these postures are maintained are important in preventing fixed and structural deformity. These are considered to be the prime causes of deformity. Whilst surgery is often necessary, it should be seen as complementary to an early postural regime, one part of which is the position in which a child sits.
\end{abstract}

\section{Introduction}

When designing or fitting seating there are many factors to consider. A particularly important factor is deformity and the problem of accommodating and supporting existing deformity whilst preventing further deterioration.

The causes of deformity are legion (Fig. 1) This paper will consider those often referred to as "developmental deformities" and in particular those caused by cerebral palsy and profound mental retardation.

\section{Deformity}

Understanding of the mechanisms involved in the appearance of developmental deformity is not complete, but it is beginning to look as though it is sufficient to form a rationale for action. Even less than twenty years ago, many people considered that disparity of muscle strength was the sole cause of deformity in growing children and cited polio as the

All correspondence to be addressed to D. Scrutton, Newcomen Centre, Guy's Hospital, St Thomas Street, London SE1 9RT, UK. example. It was said that a difference of two muscle grades on the Oxford strength scale between agonist and antagonist would produce deformity as the child grew. Yet what did that scale measure? Not the absolute strength of a muscle group in relation to its opposing group, but its strength relative to its normal strength as measured by its ability to move the appropriate body segment in relation to gravity and load. Thus on the Oxford scale a normal person's

CONGENITAL Born with deformity

Shape
Number
Size
Joint mobility
Born with defect tending to deformity
e.g. Muscular dystrophy
Spinal muscular atrophy
Brittle bones
Spina bifida
Retts
Cerebral palsy
Profound mental retardation

\begin{tabular}{|c|c|}
\hline \multirow[t]{3}{*}{ ACQUIRED } & $\begin{array}{l}\text { Trauma } \\
\text { Shape, number, size, joint } \\
\text { mobility } \\
\begin{aligned} \text { Neurological } & - \text { Peripheral } \\
& - \text { Spinal } \\
& - \text { C.N.S. }\end{aligned}\end{array}$ \\
\hline & $\begin{array}{l}\text { "Disease" } \\
\text { e.g. Stroke } \\
\text { Multiple sclerosis } \\
\text { Rheumatoid arthritis } \\
\text { Idiopathic scoliosis } \\
\text { Polionyelitis } \\
\text { Meningitis/encephalitis }\end{array}$ \\
\hline & $\begin{array}{l}\text { Therapeutic } \\
\text { e.g. Frog plasters }\end{array}$ \\
\hline
\end{tabular}

Fig. 1. The causes of deformity. 
plantarflexors and dorsiflexors both score 5 (and so are "equal") in spite of the fact that usually, the platarflexors can exert 17 times the torque of the dorsiflexors (Perry, 1985). Why then does a normal person remain undeformed? Considerations such as this led some physiotherapists working with cerebral palsy and profound mental retardation to assume that posture was involved in some way (Scrutton and Gilbertson, 1975). The normal person was seen as having postural "balance" across each joint (whatever that might mean) and so does not deform. Whether deformity was caused directly by a central process (the "imbalanced" central nervous system (CNS) directly dictating a body shape to match its postural needs) or by a peripheral process (secondary to the postural imbalance) was not clearly agreed or often even discussed.

Sharrard (1971) has shown very clearly how he pictured the mechanism, believing that the growing bone applied a force to the muscles and all other structures which grew in response. In the case of muscle strength imbalance, this produced greater growth in one muscle group than another owing to different forces being applied to them (Fig. 2). Very little was ever

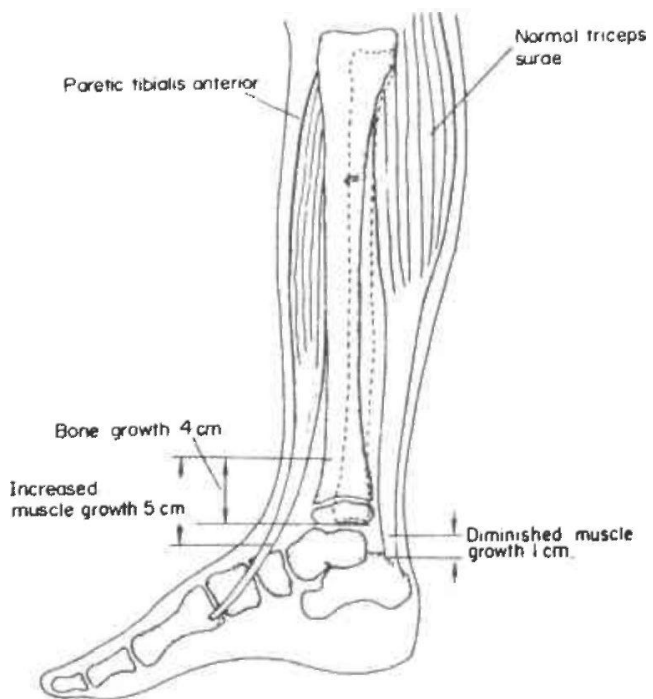

Fig 2. Tension as a factor in muscle growth. The normal muscle is under diminished tension from its antagonist and receives less stimulus to grow; the paretic muscle is effectively under increased tension and shows abnormal growth in length.

(Figure reprinted from Paediatric Orthopaedics and Fractures, W. J. W. Sharrard, 1971 by kind permission of Blackwell Scientific Publications.) written about the growth of any tissue other than bone and often it was referred to as "hypertrophy of length" on the assumption, often stated, that no new muscle tissue grew, it simply lengthened; although sarcomeres in "contracted" muscle are seen to be elongated but fewer in number (Tabary, 1971). It may seem unlikely that the CNS should directly dictate muscle length, but it was the hypothesis favoured by the writer at that time. This was partly because of the analogous skeletal undergrowth (hemihypoplasia) seen in most children with congenital hemiplegia. This hypoplasia appears to bear no relationship to the degree of movement disability or to the circulation in those limbs (Holt, 1961) and cannot be explained as a peripheral phenomenon secondary to under-use. The author considered that the likely mechanism was an example of the le Chatelier-Braun principle that a system in equilibrium always tends to regain its equilibrium when any constraint is applied to it. The "constraint" in this case is bone growth and the equilibrium in the normal person requires a balanced muscle growth response. In cerebral palsy an unequal growth response is needed to match the incorrect equilibrium determined by the damaged CNS (Scrutton and Gilbertson, 1975). This principle still appears to apply to these mechanisms, but peripherally. At the time it led the author to some (now) unlikely conclusions regarding treatment.

However, to complicate the issue, it can be observed that actual contracture of muscle and other tissue can also occur in the absence of growth. So any growth-related mechanism is not the only one which might affect children's muscles. This introduces the word "contracture" and some clarification of terminology is probably needed. In this article, several terms relating to the length of muscle (that is muscle and tendon together) will be used:

Contracture Shortening of a muscle which consequently can no longer extend to the length it once could.

Mobile deformity
A posture maintained by a patient which can nevertheless be fully corrected by the 
examiner. It is a deformity of posture rather than of anatomy.

Fixed deformity A limitation of range of movement (i.e. angular movement at a joint) caused by a muscle or group of muscles not being sufficiently extensible. There can be causes of fixed deformity other than muscular but that is not immediately part of this discussion.

Structural Change of bony shape or loss deformity of joint integrity (subluxation or dislocation).

Developmental A fixed or structural deformity deformity which occurs while the body is still growing as a consequence of the forces applied (i.e. the manner in which the body is used).

The gastrocnemius muscles of normal mice lengthen or grow, like human muscle, to accommodate bone growth and consequently a full range of ankle dorsiflexion is maintained. However, the gastrocnemii of (congenital) paraplegic mice do not. From birth to maturity the muscle/tendon growth is only $55 \%$ of bone growth and thus fixed deformity limits dorsiflexion significantly (Ziv et al., 1984). Furthermore, Ziv and his colleagues demonstrated that - in this muscle approximately $1 / 3$ of the growth occurred in the Achilles tendon and $2 / 3$ in the muscle; but nearly $70 \%$ of the muscle growth occurred at the distal musculo-tendinous junction, which they refer to as the "muscle growth-plate". The growth occurs by the creation of sarcomeres (the contractile unit of myofibrils) which can be thought of as the "transient element" of the muscle, that is the element which comes and goes as circumstances dictate.

What happens if a muscle is fixed in one position? Inactivity might (and does) cause changes, but there is more involved than the effect of inactivity (Williams and Goldspink, 1984); for the changes vary depending on whether the muscle is fixed in a lengthened or shortened position. Williams and Goldspink go on to suggest that the changes seen (a proportional increase in connective tissue) in muscles immobilised in the shortened position are "likely to result in the reduced elasticity observed in immobilised muscles. Similar changes may occur whenever muscle is working at a shortened length".

For how long does a muscle need to be stretched (and what is meant by "stretched"?) to maintain its fully functional length. Tardieu et al. (1988)* studied the range of movement of the soleus muscle throughout the day in $\mathbf{1 0}$ children whith cerebral palsy - 5 with hemiplegia and 5 with diplegia - as well as 5 children who were not handicapped. They concluded that 6 hours stretch in 24 hours was needed to maintain length and described precisely how they defined "stretch".

Structural deformity is usually associated with fixed deformity and within these disorders refers primarily to the hip joint - a major problem in seating. Once again, the mechanism of producing hip dysplasia is not fully understood but the prime cause could be summed up as persistently abnormal forces acting on the femoral head/acetabulum interface probably during the first four years of life. These are brought about by delayed weightbearing and by abnormal posture usually adduction with internal rotation or, less often, abduction with external rotation of the femur. Undoubtedly fixed deformity is strongly associated with hip dysplasia in these children but it is doubtful that it is strictly speaking a cause. Rather, the same circumstances that produce fixed deformity also produce dysplasia and, because persistence of posture causes dysplasia, surgical correction of fixed deformity may be necessary to prevent it. Reimers (1980) in an exhaustive monograph on hip dysplasia in cerebral palsy found that anterior obturator neurectomy on its own was as effective in correcting dysplasia as neurectomy combined with adductor tenotomy.

The age at which those abnormal forces act is also important. Vidal (1985) found in his series of 292 hips in 158 cerebral palsied children that acetabular obliquity (one way in which acetabular dysplasia can be seen on $\mathrm{x}$-ray) did not appear until 30 months, or unless the *See subsequent correspondence in Developmental Medicine and Child Neurology, 1989, 31, 117-118. 
femoral head had migrated lateral to the bony acetabular margin by more than $20 \%$ of the head's (bony) width (Vidal, 1985). This is not always so, but was for his series and probably for the majority of cerebral palsy children. Harris et al. (1975) amongst others showed that natural corrective remodelling of the acetabulum gets increasingly less likely after 4 years; and Kalen and Bleck (1985) found that soft tissue surgery was less effective in producing hip stability after age 5 years. For a more detailed review see Scrutton (1989).

Thus this period from birth to (say) 5 years and perhaps more particularly from 30 months to 4 years - is critical for hip development and early weight-bearing should be encouraged with avoidance of a persistent posture. Fortunately, both these aims are consistent with basic seating aims as follows:

1. the pelvis needs to be correctly positioned for both spinal and lower limb posture;

2. correct femoral and foot position gives a more secure base;

3. ease of transfer is necessary to allow standing.

\section{REFERENCES}

Harris, N、 H., Lloyd Roberts, G. C., Gallien, R. (1975). Acetabular development in congenital dislocation of the hip, with special reference to the indications for acetabuloplasty and pelvic or femoral realignment osteotomy. J. Bone Joint Surg., 57b, 46-52.

HolT, K. S. (1961). Growth disturbances. In: Hemiplegic cerebral palsy in children and adults, a report of an international study group, Wills Hall, Bristol, 1961. (Little Club Clinics in Developmental Medicine, No 4). - London: The National Spastics Society.

Kalen, V., Bleck, E. E. (1985). Prevention of spastic paralytic dislocation of the hip. Dev. Med. Child Neurol., 27, 17-24.
Perry, J. (1985). Personal Communication cited. In: Orthopaedic management in cerebral palsy E. E. Beck. Clinics in Developmental Medicine, No 99/ 100. - London: MacKeith Press, Blackwell Scientific, 1987.

Reimers, J. (1980). The stability of the hip in children: a radiological study of the results of muscle surgery in cerebral palsy. Acta Orthop. Scand. Suppl., 184.

Scrutton, D. R., Gilbertson, M. (1975). Physiotherapy in paediatric practice. - London: Butterworth.

SCRUtTon, D. R. (1989). The early management of hips in cerebral palsy. Dev. Med. Child Neurol., 31 $108-116$.

Sharrard, W. J. W. (1971). Paediatric orthopaedics and fractures. - Oxford: Blackwell Scientific Publications.

Tardieu, C., Lespargot, A., Tabary, C., Bret, M. D. (1988). For how long must the soleus muscle be stretched each day to prevent contracture? Dev. Med. Child Neurol., 30, 3-10.

Vidal, J., Deguillaume, P., Vidal, M. (1985). The anatomy of the dysplastic hip in cerebral palsy related to prognosis and treatment. Int. Orthop., 9 , 105-110.

Williams, P. E., Goldspink, G. (1984). Connective tissue changes in immobilised Muscle. J. Anat., $138,343-350$.

Zit. 1., Biackatun. N., Rang, M., Koreska, J. (1984). Muscle growth in normal and spastic mice. Det. Med. Child Neurol. 26. 94-99.

The following two papers provide essential guidance in their subject areas. They are not referred to in this paper as they appeared subsequent to its writing.

O'Dinger, N、 J., Neilson, P、D., Nash, J. (1989). Mechanisms of muscle growth related to muscle contracture in cerebral palsy. Dev. Med. Child Neurol., 31, 543-552.

WRIGHT, J., RANG, D. M. (1990). The spastic mouse and the search for an animal model of spasticity in human beings. Clin. Orthop., 253, 12-19. 